\title{
Anatomical Evidence for an Ascending Somatosensory Pathway to the Telencephalon in Crocodiles, Caiman crocodilus*
}

\author{
M.B. Pritz ${ }^{1}$ and R. G. Northcutt ${ }^{2}$ \\ ${ }^{1}$ Department of Surgery, Section of Neurological Surgery, University of Michigan Medical Center, Ann Arbor, MI 48109, USA \\ ${ }^{2}$ Division of Biological Sciences, University of Michigan, Ann Arbor, MI 48109, USA
}

\begin{abstract}
Summary. A series of experiments in Caiman crocodilus that outlines an ascending somatosensory pathway to the telencephalon is described. This telencephalic somatosensory area was found to correspond to a region high in succinate dehydrogenase activity.
\end{abstract}

Key words: Caiman crocodilus - Reptiles Somatosensation - Succinate dehydrogenase

The dorsal ventricular ridge (DVR) is a prominent cellular mass located in the ventrolateral wall and extending into the lateral ventricle of the telencephalon of most reptiles. Architectonic descriptions of the DVR (Rose 1923; Riss et al. 1969) reveal a number of subdivisions which, in Caiman crocodilus, do not precisely correspond to experimentally determined auditory (Pritz 1974) and visual (Pritz 1975) projections from the thalamus to the DVR. The DVR of Caiman, which is equivalent to the dorsolateral area of Huber and Crosby (1926), exhibits several distinct regions of high succinate dehydrogenase (SDH) activity of which two correspond to thalamotelencephalic auditory and visual targets (Pritz and Northcutt 1977). We provide evidence that an additional DVR region high in SDH is the target of an ascending somatosensory pathway.

To determine which thalamic nuclei received non-facial somatosensory input, we made 4 cervical spinal cord hemisections (Northcutt and Pritz 1978) and a dorsal obex lesion in juvenile Caiman crocodilus. Each brain was then processed in a standard fashion for the demonstration of degenerated axons

* This research was partly supported by NIH grant NS 11006 Offprint requests to: Michael B. Pritz, M.D. Ph.D., University Hospitals, 1405 East Ann Street, Ann Arbor, MI 48109, USA and terminals (Northcutt and Pritz 1978). These cases revealed an ascending pathway that coursed through the rostral pole of the tectum to terminate in nucleus medialis (Northcutt and Pritz 1978; Fig. 1A). However, terminal degeneration in nucleus medialis was greater following the obex lesion than after cervical hemisection. Nucleus medialis (Fig. 1B), which is located in the caudal dorsal thalamus, appears as a crescent-shaped nucleus that extends from the medial border of nucleus rotundus caudally to the level of nucleus reuniens where it occupies a more dorsomedial position (Huber and Crosby 1926).

Our initial effort to identify the central connections of nucleus medialis made use of a stereotaxically placed microelectrode lesion in a single juvenile Caiman who survived for 10 days at $30^{\circ} \mathrm{C}$ (see Pritz 1975 for a detailed account of the procedure). The degenerated axons that resulted from this lesion, which destroyed a dorsolateral and dorsocentral portion of nucleus medialis, collected along the medial and lateral aspects of nucleus rotundus to enter the dorsal peduncle of the lateral forebrain bundle. Rostrally, these axons pass through, and perhaps synapse on, interposed neurons in the ventrolateral area before terminating in a central portion of the dorsolateral area (Fig. 1C). This area of terminal degeneration is located lateral to the auditory telencephalic projection zone of nucleus reuniens pars centralis and caudomedial to the visual telencephalic projection area of nucleus rotundus. This particular target of nucleus medialis appears to coincide, at least in part, with an area of increased SDH activity (see Fig. 1 in Pritz and Northcutt 1977). Unfortunately, this experiment was compounded by a second lesion in a medial portion of the midbrain tegmentum. Degenerating axons were seen to terminate in the ipsilateral nucleus of the lateral olfactory tract in addition to the dorsolateral area described 


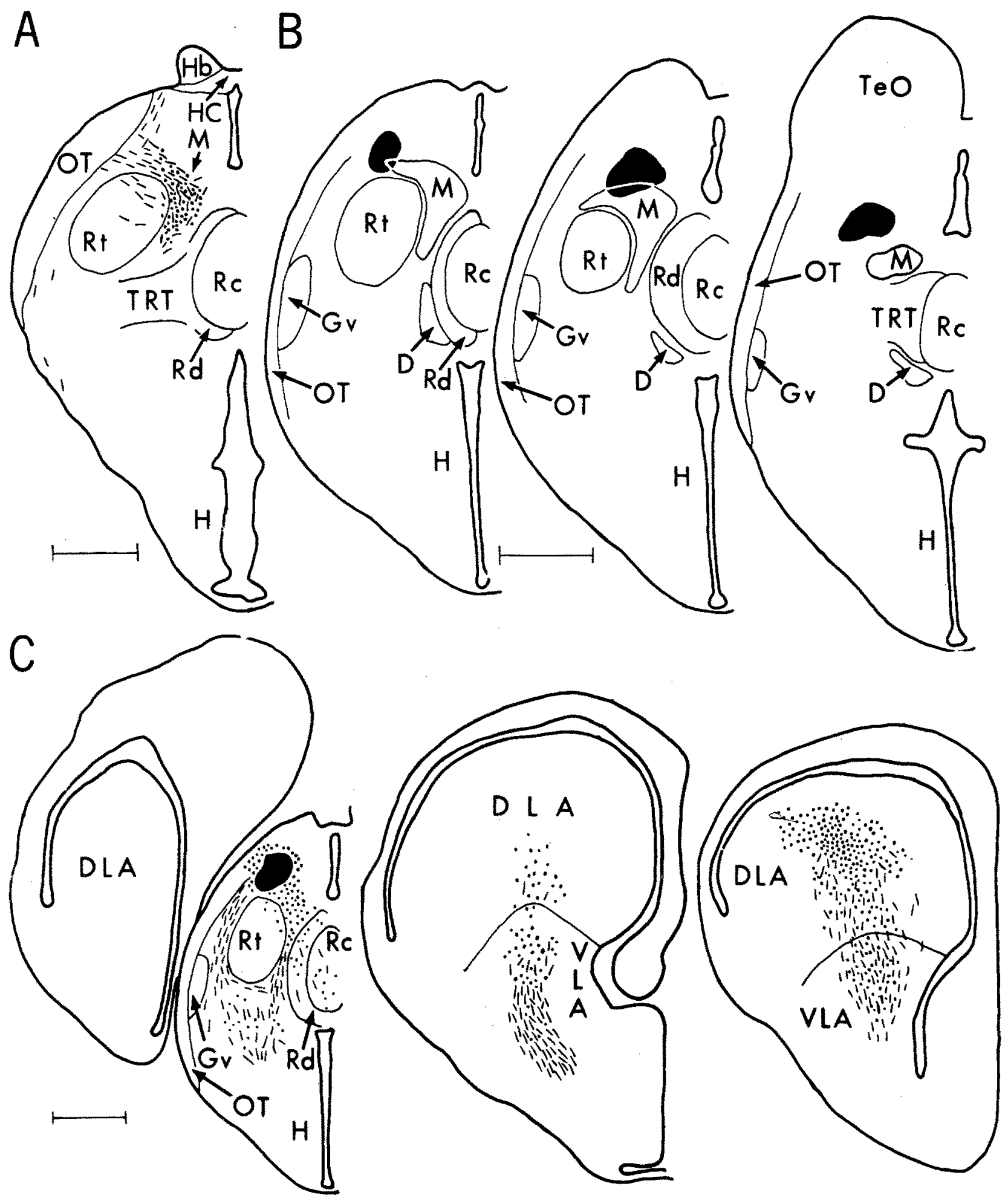

Fig. 1A-C. Ascending somatosensory connections. A illustrates the distribution of degenerated axons and axon terminals after a dorsal hemisection of the obex region. B shows the locus and extent of a small lesion (solid blackened area) of the dorsolateral and dorsocentral portion of nucleus medialis. $\mathbf{C}$ demonstrates the pattern of degeneration seen after the lesion made in $\mathbf{B}$. The section that demonstrates this lesion in $\mathbf{C}$ is located halfway between the first two sections in $\mathbf{B}$. Short line segments represent degenerated axons while dots indicate terminal degeneration. All drawings are of transverse sections. Abbreviations: D, nucleus diagonalis; DLA, dorsolateral area; Gv, ventral geniculate nucleus; $\mathrm{H}$, hypothalamus; $\mathrm{Hb}$, habenula; $\mathrm{HC}$, habenular commissure; $\mathrm{M}$, nucleus medialis; OT, optic tract; $\mathrm{Rc}$, nucleus reuniens pars centralis; $\mathrm{Rd}$, nucleus reuniens pars diffusa; $\mathrm{Rt}$, nucleus rotundus; $\mathrm{TeO}$, optic tectum; TRT, tecto-reuniens tract; VLA, ventrolateral area. Bar scales represent $1 \mathrm{~mm}$ 

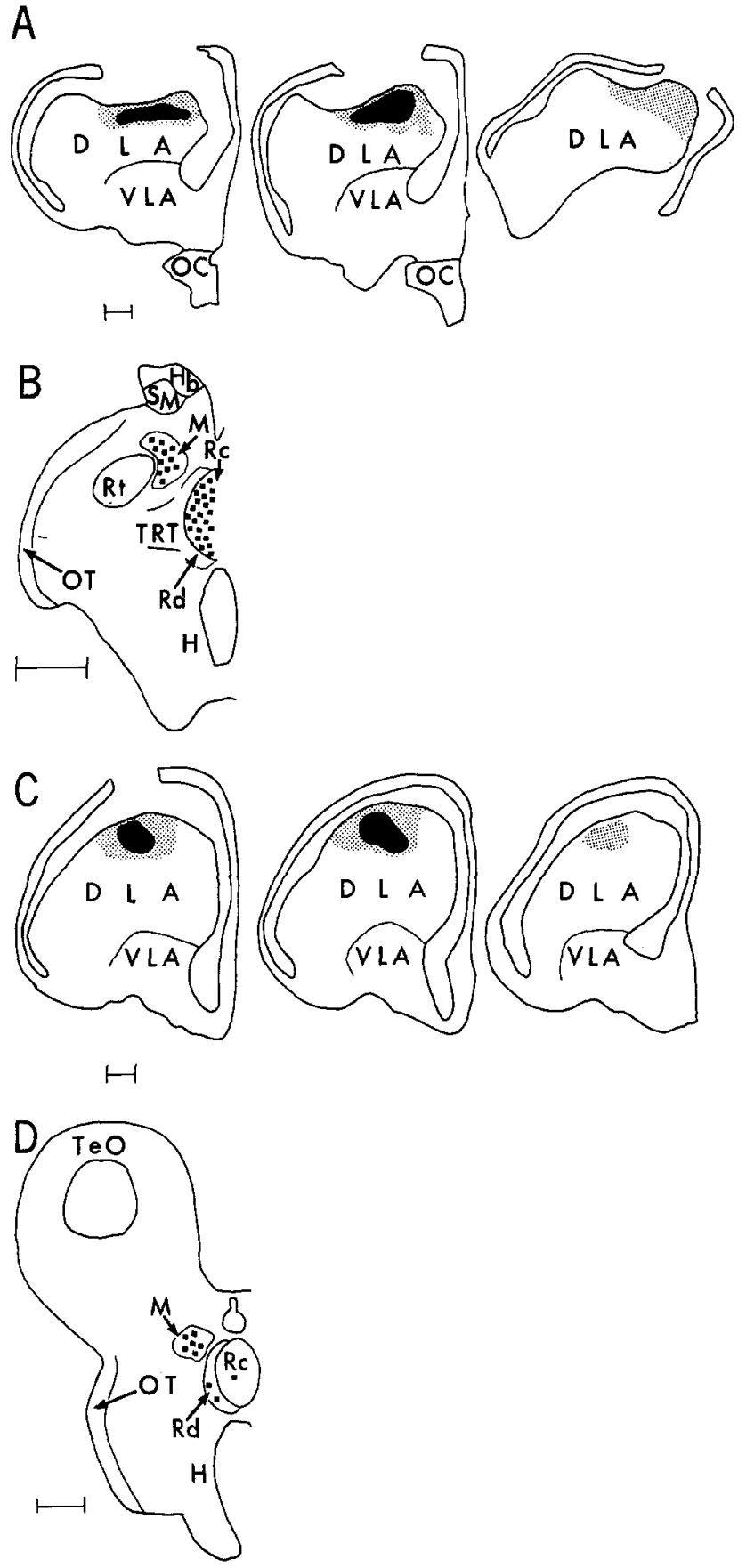

Fig. 2A-D. Afferents to the telencephalon as demonstrated by the retrograde transport of horseradish peroxidase (HRP). A illustrates a $1200 \mathrm{nl}$ injection of HRP while $\mathbf{C}$ shows a $700 \mathrm{nl}$ injection. The locus and extent of the reaction product are seen in the three transverse sections in $\mathbf{A}$ and $\mathbf{C}$. The blackened area represents the most intense reaction product while the stippled area represents the less intense reaction product. The distribution of neurons labelled after each injection is shown by squares in transverse sections B and D. Abbreviations: DLA, dorsolateral area; $\mathrm{H}$, hypothalamus; $\mathrm{Hb}$, habenula; $\mathrm{M}$, nucleus medialis; $\mathrm{OC}$, optic chiasm; OT, optic tract; Rc, nucleus reuniens pars centralis; Rd, nucleus reuniens pars diffusa; Rt, nucleus rotundus; SM, stria medullaris; TeO, optic tectum; TRT, tecto-reuniens tract; VLA, ventrolateral area. Bar scales represent $1 \mathrm{~mm}$ above. Unpublished observations indicated that midbrain transections produce degeneration in the nucleus of the lateral olfactory tract but not in the dorsolateral area. Thus, this additional degeneration was attributed to the second ablation and is not charted. Also, the possibility that the pattern of degeneration seen after the lesion of nucleus medialis was produced by the interruption of axons that passed through, but did not originate in, nucleus medialis, could not be excluded by this experiment alone.

To resolve these problems, we made pressure injections of horseradish peroxidase (HRP) with glass micropipettes into the telencephalons of two additional juvenile Caiman anaesthetized with intramuscular methohexital sodium. The calvarium over the midportion of the telencephalon was removed and the DVR was exposed transcortically. After a survival period of 5 (Case 1) or 7 days (Case 2 ) at 21 to $25^{\circ} \mathrm{C}$, each animal was given an overdose of methohexital sodium and perfused transcardially with $0.7 \%$ saline followed by $2 \%$ glutaraldehyde. Brains were embedded in gelatin, sectioned at $40 \mu$, and reacted according to a standard protocol with diaminobenzidine (LaVail and LaVail 1974) and odianisidine (Coleman et al. 1976). Case 1 received a large, unilateral injection of HRP (1200 $\mathrm{nl}$ of a $25 \%$ aqueous solution) into the DVR (Fig. 2A) which resulted in massive labelling of neurons in nucleus reuniens pars centralis and nucleus medialis ipsilateral to the injection (Fig. 2B). No neurons were labelled in the midbrain tegmentum, the site of the second lesion suspected of giving rise to the terminal degeneration seen in the nucleus of the lateral olfactory tract. A previous experiment had shown that lesions restricted to nucleus reuniens pars centralis result in terminal degeneration localized to a circumscribed area of the ipsilateral telencephalon (Pritz 1974). Thus, the additional labelled neurons in nucleus medialis were attributed to the more lateral portion of the injected dorsolateral area (Fig. 2A). Because of the large extent of this injection, Case 2 received smaller bilateral injections of a $25 \%$ aqueous solution of HRP, 600 and $700 \mathrm{nl}$. These more restricted injections (Fig. 2C) labelled neurons in the more caudal part of nucleus medialis and an occasional neuron in nucleus reuniens (Fig. 2D). A precise comparison of the locus of HRP injections (Fig. 2A, 2C) with the distribution of terminal degeneration after lesion of nucleus medialis is complicated. The HRP brains were not blocked in the same plane as the lesioned brain, and some distortion of the telencephalic hemispheres occurred in the brains processed for HRP. However, careful review of the material indicates significant overlap 
between the locus of HRP injection, labelling neurons in nucleus medialis, and the telencephalic distribution of terminal degeneration seen after the lesion of nucleus medialis.

Taken together these HRP cases resolve two questions that were not able to be answered by the case with the lesion in nucleus medialis. First, the pattern of degeneration seen after, and attributed to, the lesion of nucleus medialis was indeed due to damage to this nuclear group and not to axons merely passing through nucleus medialis. Second, the partial lesion of the midbrain tegmentum was not the source of degenerated axons seen entering the lateral forebrain bundle to terminate in the dorsolateral area.

These experiments provide a preliminary outline of the neural circuitry underlying the transmission of non-facial somatosensory information to the telencephalon in Caiman crocodilus. Comparable studies of other reptiles are not available. However, scattered reports suggest that the ascending somatosensory pathways we describe are not unique to Caiman. Spinal cord hemisections in several reptiles have revealed projections to a dorsal thalamic region, nucleus intermedius dorsalis thalami (Ebbesson 1967, 1969). On the other hand, lesions of the dorsal column nuclei in the monitor lizard, Varanus bengalensis, have revealed a pathway terminating in a thalamic area labelled the ventrobasal complex (Ebbesson 1978). Furthermore, thalamic nuclei other than those we term nucleus reuniens pars centralis and nucleus rotundus in Caiman are reported to project to a restricted portion of the DVR in lizards (Lohman and Van Woerden-Verkley 1978) and turtles (Parent 1976). However, additional anatomical details are needed before somatosensory organization in Caiman and other reptiles can be understood.

Acknowledgements. We thank the Detroit Zoological Park and the Michigan Department of Natural Resources for their help in obtaining some of the Caiman used in these studies. All Caiman were obtained before enactment of Federal Law PL-91-135 and are in compliance with Michigan Act 210, PA 1972 (Michigan) by license to the University of Michigan.

\section{References}

Coleman DR, Scalia F, Cabrales E (1976) Light and electron microscopic observations on the anterograde transport of horseradish peroxidase in the optic pathway in the mouse and rat. Brain Res 102: 156-163

Ebbesson SOE (1967) Ascending axon degeneration following hemisection of the spinal cord in the Tegu lizard (Tupinambis nigropunctatus). Brain Res 5: 178-206

Ebbesson SOE (1969) Brain stem afferents from the spinal cord in a sample of reptilian and amphibian species. Ann NY Acad Sci 167: 80-101

Ebbesson SOE (1978) Somatosensory pathways in lizards: The identification of the medial lemniscus and related structures. In: Greenberg N, MacLean PD (eds) Behavior and neurology of lizards. An interdisciplinary colloquium. Dept. Health, Education, and Welfare Publication No. (ADM) 77-491, Rockville, MD, pp 91-104

Huber GC, Crosby EC (1926) On thalamic and tectal nuclei and fiber paths in the brain of the American alligator. J Comp Neurol 40: 97-227

LaVail JH, LaVail MM (1974) The retrograde intraaxonal transport of horseradish peroxidase in the chick visual system. A light and electron microscopic study. J Comp Neurol 157: 303-358

Lohman AHM, Woerden-Verkley I van (1978) Ascending connections to the forebrain in the Tegu lizard. J Comp Neurol 182: 555-574

Northcutt RG, Pritz MB (1978) A spinothalamic pathway to the dorsal ventricular ridge in the spectacled caiman, Caiman crocodilus. Anat Rec 190: 618-619

Parent A (1976) Striatal afferent connections in the turtle (Chrysemys picta) as revealed by retrograde axonal transport of horseradish peroxidase. Brain Res 108: 25-36

Pritz MB (1974) Ascending connections of a thalamic auditory area in a crocodile, Caiman crocodilus. J Comp Neurol 153: $199-214$

Pritz MB (1975) Anatomical identification of a telencephalic visual area in crocodiles: ascending connections of nucleus rotundus in Caiman crocodilus. J Comp Neurol 164: 323-338

Pritz MB, Northcutt RG (1977) Succinate dehydrogenase activity in the telencephalon of crocodiles correlates with the projection areas of sensory thalamic nuclei. Brain Res 124: 357-360

Riss W, Halpern M, Scalia F (1969) The quest for clues to forebrain evolution - the study of reptiles. Brain Behav Evol 2: $1-50$

Rose M (1923) Histologische Lokalisation des Vorderhirns der Reptilien. J Psychol Neurol (Lpz) 29: 219-272

Received December 4, 1980 